\title{
Isolation and characterization of novel microsatellite markers from the sika deer (Cervus nippon) genome
}

\author{
Y.M. Li*, C.Y. Bai, W.P. Niu, H. Yu, R.J. Yang, S.Q. Yan, J.Y. Zhang, M.J. Zhang \\ and Z.H. Zhao \\ College of Animal Science, Jilin University, Changchun, China \\ *These authors contributed equally to this study. \\ Corresponding authors: M.J. Zhang / Z.H. Zhao \\ E-mail: mjzhang@jlu.edu.cn / zhzhao@jlu.edu.cn \\ Genet. Mol. Res. 14 (3): 11524-11534 (2015) \\ Received December 3, 2014 \\ Accepted June 18, 2015 \\ Published September 28, 2015 \\ DOI http://dx.doi.org/10.4238/2015.September.28.4
}

ABSTRACT. Microsatellite markers are widely and evenly distributed, and are highly polymorphic. Rapid and convenient detection through automated analysis means that microsatellite markers are widely used in the construction of plant and animal genetic maps, in quantitative trait loci localization, marker-assisted selection, identification of genetic relationships, and genetic diversity and phylogenetic tree construction. However, few microsatellite markers remain to be isolated. We used streptavidin magnetic beads to affinity-capture and construct a $(C A)_{n}$ microsatellite DNA-enriched library from sika deer. We selected sequences containing more than six repeats to design primers. Clear bands were selected, which were amplified using non-specific primers following PCR amplification to screen polymorphisms in a group of 65 unrelated sika deer. The positive clone rate reached $82.9 \%$ by constructing the enriched library, and we then selected positive clones for sequencing. There were 395 sequences with CA repeats, and the CA repeat number was 4-105. We selected sequences containing more than six repeats to design primers, of which 297 pairs were designed. We next selected clear bands and used 
non-specific primers to amplify following PCR amplification. In total, 245 pairs of primers were screened. We then selected 50 pairs of primers to randomly screen for polymorphisms. We detected 47 polymorphic and 3 monomorphic loci in 65 unrelated sika deer. These newly isolated and characterized microsatellite loci can be used to construct genetic maps and for lineage testing in deer. In addition, they can be used for comparative genomics between Cervidae species.

Key words: Sika deer; Microsatellite markers; Enriched library; Polymorphism

\section{INTRODUCTION}

Microsatellites, or simple sequence repeats (SSRs), are also known as short tandemrepeats (Tautz and Renz, 1984; Stallings et al., 1991). SSRs are tandem-repeated motifs of 1-6 bp found in all prokaryotic and eukaryotic genomes. Microsatellites are present both in coding and noncoding regions. Because they are highly polymorphic, microsatellites have been extensively used in forensics, genetic mapping, population genetics, evolutionary studies, and investigations of social systems (Chakraborty et al., 1997; Buchholz et al., 1998; Chowdhury and Bansal, 2001; Jakše and Branka, 2001). A flanking sequence is located at particular chromosomal locations, and the repeat length of core tandem-repeat sequences ranges from $10 \mathrm{~s}$ to $100 \mathrm{~s}$ of bp. Because of the different numbers of repetitions and degrees of repeat units, microsatellite loci within species and individuals are polymorphic. There are many microsatellite markers with widespread and even distributions, and high levels of polymorphisms. With rapid and convenient detection and automated analysis, microsatellite markers have become widely used in plant and animal genetic mapping, quantitative trait locus (QTL) localization, marker-assisted selection (MAS), and in the identification of genetic relationships and genetic diversity (Crittenden et al., 1993).

Molecular genetic maps provide insight into the genomic and chromosomal localization of cloned genes, and provide a framework for the identification and location of major genes associated with economically important traits (Crittenden et al., 1993). In recent years, rapid advances have been made in the development of molecular genetic maps. High-density linkage maps are now available for many farm animals, such as cattle, pigs, and goats (Huang et al., 2005). In contrast, mapping studies in Bovidae species are much less advanced, similarly in the Cervidae. To construct saturated genetic maps for more Cervidae species, the isolation of polymorphic genetic markers, particularly microsatellite markers, is required (Huang et al., 2005).

The sika deer (Cervus nippon) is an endangered cervid endemic to mainland and insular Asia (Lü et al., 2006). Although close to extinction, it is also one of the most active members of the ecosystem, and it is an ecologically significant animal (Zhang, 2007). Changchun has the world's earliest history of deer breeding and the largest number of varieties and breeding places. The deer in Shuang-Yang represent the first artificial cultivation of improved varieties in China, as well as throughout the world. The velvet is of high quality and yield. This species has many advantages, including stable genetic properties, resistance to crude feeding, adaptability, and a high value of breeding.

Due to their abundance in genomes, high mutation rates, and multi-allelic nature (Ellegren, 2000), microsatellites markers are one of the best choices for use in population genetics (Sahoo and Kashyap, 2005). Microsatellites play an important role in the construction of genetic maps, 
genomic structure analysis, QTL mapping, MAS, phylogenetic tree construction, genetic diversity assessment and detection, population genetic structure analysis, genetic management of species, and in the establishment of protection units. However, the genetic status of populations has not been well studied because of a lack of appropriate genetic markers. Molecular markers, including randomly amplified polymorphic DNAs and restriction fragment length polymorphisms, are not always diagnostic in detecting genetic variation within a population of sika deer because the genetic variability of those markers is reduced to an undetectable level in some cases (Tamate and Tsuchiya, 1995; Tamate et al., 1995). Searching in current major bioinformatics database, such as GenBank, EMBL, DDBJ, found that, up to today, of the 200+ microsatellite markers used to study deer, 30 were isolated from the deer genome, from species such as white deer and reindeer, and the remaining markers were amplified from "borrowed" bovine animals and other deer.

To overcome such difficulties, we sought to identify microsatellite markers of the genus Cervus (Tamate et al., 1995). Thus, we concentrated on constructing an enriched Sika microsatellite library by isolating and characterizing a number of microsatellite markers. In addition, this research can provide many new genetic markers for deer. The antlers, kidneys, blood, placenta, and sinew of deer are all used in traditional Chinese medicine. If we can identify new microsatellite loci from the enriched microsatellite library, we also can create new drug formulations to allow the clinical diagnosis and treatment of many rare diseases where the molecular mechanisms are understood. For linkage and comparative genetic mapping, parentage testing, population genetics, and phylogenetic studies in Cervidae, we isolated and characterized polymorphic microsatellite markers in sika deer. After reading the literature pertaining to microsatellite libraries, we decided to utilize the strong affinity between biotin and streptavidin to construct the microsatellite library (Reed et al., 2003). Using this approach, we isolated and characterized a number of microsatellite markers. This research may provide a foundation for future genetic studies on deer. Through this study, we selected multiple microsatellite sequences and designed primers to permit screening of these specific microsatellite markers.

\section{MATERIAL AND METHODS}

\section{Sika deer DNA isolation}

Sixty-five sika deer (24 males and 40 females) were randomly selected from a deer farm at Jilin Changshuang Deer Industry Co., Ltd. and Special Local Product Development Group Co., Ltd. Genomic DNA was isolated by phenol/chloroform extraction and ethanol precipitation from 33 sika deer tissue samples [28 tissue samples from the kidneys (6 males and 22 females), one tissue sample from the cartilage (male), one tissue sample from the lungs (male), one tissue sample from the brain (male), one tissue sample from the liver (male)] and 32 blood samples (14 males and 18 females) from 65 unrelated individuals.

\section{Construction and screening of a genomic library enriched with $(C A)_{n}$ repeats}

To obtain a higher number of sika deer microsatellite markers, we constructed a genomic library enriched with $(\mathrm{CA})_{\mathrm{n}}$ repeats, following a combination of modified procedures (Kandpal et al., 1994; Fischer and Bachmann, 1998; Paniego et al., 2002; Huang et al., 2005). Genomic DNA from sika deer was digested with the restriction enzyme $\mathrm{Mbol}$, and fragments 
ranging in size from 400 to $1000 \mathrm{bp}$ were recovered from an agarose gel with a mass fraction of $1.5 \%$ under $60 \mathrm{~V}$ for $1 \mathrm{~h}$. The recovered fragments $(600 \mathrm{ng})$ were ligated to an adaptor (5 $\mu \mathrm{g}$, a phosphorylated Linker A 5'-pGATCGCAGAATTCGCACGAGTACTAC-3' and Linker B 5'-GTAGTACTCGTGCGAATTCTGC-3'), which was generated by heating both components to $94^{\circ} \mathrm{C}$ for $4 \mathrm{~min}$, cooling to $70^{\circ} \mathrm{C}$ for $10 \mathrm{~min}$ and cooling to room temperature by incubation at $16^{\circ} \mathrm{C}$ for $12 \mathrm{~h}$ with T4 DNA ligase (Takara). The adaptor-ligation fragments were denatured at $65^{\circ} \mathrm{C}$ for $15 \mathrm{~min}$, and PCR was performed in a $25-\mu \mathrm{L}$ reaction mix containing $20 \mu \mathrm{M}$ DNA adaptor-ligation, $2.5 \mathrm{mM}$ 10X ExTaq Buffer ( $\mathrm{Mg}^{2+}$ plus), $50 \mu \mathrm{M}$ Linker B as a primer, $2.0 \mathrm{mM}$ d NTPs, and $0.625 \mathrm{U}$ Taq polymerase. Amplification conditions were as follows: $94^{\circ} \mathrm{C}$ for 3 min followed by 15 cycles at $94^{\circ} \mathrm{C}$ for $1 \mathrm{~min}$, an annealing temperature of $58^{\circ} \mathrm{C}$ for $1 \mathrm{~min}$ and $72^{\circ} \mathrm{C}$ for $1 \mathrm{~min}$, with a final extension at $72^{\circ} \mathrm{C}$ for $7 \mathrm{~min}$. PCR fragments were separated via high-resolution polyacrylamide gel-electrophoresis. Next, hybridization screening of microsatellites was performed with biotin labeled probes and magnetic beads. The hybridization was performed in a $50-\mu \mathrm{L}$ reaction mix containing $50 \mu \mathrm{M}$ Probe [bio-(CA) $)_{15}$, $50 \mu \mathrm{M}$ Linker B, $15.0 \mu \mathrm{L} 20 \mathrm{X}$ SSC, $0.5 \mu \mathrm{L} 10 \%$ SDS, and $300 \mathrm{ng}$ PCR fragments. The PCR fragments were denatured at $95^{\circ} \mathrm{C}$ for $5 \mathrm{~min}$, followed by quick chilling in the hybridization reaction mix at $68^{\circ} \mathrm{C}$ for 1 hour. At the same time, the beads were set to balance. We placed $500 \mu \mathrm{L}$ streptavidin magnetic beads into the silica tube and then put the silica tube onto the magnetic frame for 1-2 min. Next, we added $200 \mu \mathrm{L} \mathrm{B \& W}$ to wash the streptavidin magnetic beads twice. Finally, we added $200 \mu \mathrm{L}$ solution I to wash the streptavidin magnetic beads several times until the beads became smooth and were easy to elute. We added the hybridization mixture to the streptavidin magnetic beads with a balance at $25^{\circ} \mathrm{C}$ for $20 \mathrm{~min}$. Beads were then washed three times under low stringency conditions (room temperature in 2X SSC, 1\% SDS, 10 min each), three times under high stringency conditions (in $1 \mathrm{XSSC}$ at $68^{\circ} \mathrm{C}, 15 \mathrm{~min}$ each), and twice in cold low-salt buffer $(0.15 \mathrm{M} \mathrm{NaCl}, 20 \mathrm{mM}$ Tris- $\mathrm{HCl}, \mathrm{pH} 8.0,1 \mathrm{mM}$ EDTA) for $3 \mathrm{~s}$. Finally, the beads were eluted as single-stranded fragments with $35 \mu \mathrm{L}$ elution buffer $(10 \mathrm{mM} \mathrm{Tris}-\mathrm{HCl}, \mathrm{pH}$ 8.0, $1 \mathrm{mM}$ EDTA). The final eluate $(1 \mu \mathrm{L})$ served as a template for PCR (with Linker $B$ as a unique primer, 30 cycles of $94^{\circ} \mathrm{C}$ for $1 \mathrm{~min}, 58^{\circ} \mathrm{C}$ for $1 \mathrm{~min}$, and $72^{\circ} \mathrm{C}$ for $1 \mathrm{~min}$ ) to obtain double-stranded fragments. PCR products were purified from an agarose gel with a mass fraction of 0.015 , ligated to a pMD18-T vector (Takara), and transformed into Escherichia coli DH5a-competent cells to produce a microsatellite-enriched library. The library was further screened by PCR using Linker B and $(\mathrm{CA})_{10}$ as primers.

\section{DNA sequencing and primer design}

The bacilli were used as a template for PCR [Linker B and (CA) $)_{10}$ primers were used]. PCR was performed in a $25-\mu \mathrm{L}$ reaction mix containing $1 \mu \mathrm{L}$ bacilli, $2.5 \mathrm{mM}$ 10X ExTaq Buffer ( $\mathrm{Mg}^{2+}$ plus), $50 \mu \mathrm{M}$ Linker B primer, $2.0 \mathrm{mM}$ dNTPs, and $0.625 \mathrm{U}$ Taq polymerase. Amplification conditions were $94^{\circ} \mathrm{C}$ for $3 \mathrm{~min}$ followed by 30 cycles at $94^{\circ} \mathrm{C}$ for $1 \mathrm{~min}$, annealing temperature of $58^{\circ} \mathrm{C}$ for $1 \mathrm{~min}$ and $72^{\circ} \mathrm{C}$ for $1 \mathrm{~min}$, with a final extension step of $72^{\circ} \mathrm{C}$ for $7 \mathrm{~min}$. PCR fragments were separated via high-resolution polyacrylamide gel-electrophoresis. Next, the bacilli of positive clones were sequenced in Shang-hai. The software program Primer5.0 (Paniego et al., 2002) was used to design PCR primers flanking the microsatellites that contained more than six uninterrupted repeats. Primers pairs were analyzed for all secondary structures, including hairpins, self-dimers, and cross-dimers to minimize the formation of primer dimers. We also tried to match the AT and GC content of the primers. The PCR products of all primers were expected to be between 100 and $1000 \mathrm{bp}$ in size. For subsequent work, we selected primers with a relatively narrow Tm range. 


\section{PCR amplification and polymorphism analysis}

PCR was performed in a $25-\mu \mathrm{L}$ reaction mix containing 10-50 ng genomic DNA, 2.5 mM 10X ExTaq Buffer (Mg ${ }^{2+}$ plus), $50 \mu \mathrm{M}$ Linker B as primer, $2.0 \mathrm{mM}$ dNTPs, and $0.625 \mathrm{U}$ Taq polymerase. The PCR protocol began with a denaturing step for $3 \mathrm{~min}$ at $95^{\circ} \mathrm{C}, 30$ cycles of $94^{\circ} \mathrm{C}$ for $30 \mathrm{~s}, 45^{\circ}-65^{\circ} \mathrm{C}$ for $30 \mathrm{~s}$, and $72^{\circ} \mathrm{C}$ for $30 \mathrm{~s}$, with a final extension step at $72^{\circ} \mathrm{C}$ for $7 \mathrm{~min}$. A mixture containing $2 \mu \mathrm{L}$ PCR product and $8 \mu \mathrm{L}$ denaturation buffer was made, denatured in boiling water for $10 \mathrm{~min}$, and then placed on ice for $10 \mathrm{~min}$. Next, the mixture was loaded onto a $10-12 \%$ mass fraction denaturing polyacrylamide gel for denaturing polyacrylamide gel-electrophoresis.

\section{Statistics}

According to the microsatellites sequences we obtained, we calculated the ratio of positive and non-positive clones. Statistical evaluations of the microsatellite markers, including the observed heterozygosity, number of alleles, and length of alleles were performed using the Gel-Pro analyzer 4.0 (http://www.mediacy.com.cn/cn/product/proA_D.asp).

\section{RESULTS AND DISCUSSION}

\section{Genomic DNA from sika deer digested with the restriction enzyme Mbol}

Sika deer genomic DNA was digested with the restriction enzyme $\mathrm{Mbol}$, and fragments ranging from 400 to $1000 \mathrm{bp}$ were recovered from an agarose gel with a mass fraction of $1.5 \%$ under $60 \mathrm{~V}$ for $1 \mathrm{~h}$. When a fragment was larger than $1000 \mathrm{bp}$, it would not pass the first test. In addition, if the fragment was too long, it was not easily adsorbed. Thus, if the fragment was too long, the PCR amplification was difficult. Because the restriction site for Mbol is GTAC (Fischer and Bachmann, 1998) and, in mammalian genomes, restriction sites are widely distributed, we chose to use the restriction enzyme $\mathrm{Mbol}$. Genomic DNA was uniformly cut into different sized fragments by $\mathrm{Mbol}$, ensuring both the randomness and authenticity of screening microsatellite sites.

\section{Connection between the linker and fragments generated by the restriction enzyme}

Before constructing the microsatellite library, the fragments derived from restriction digestion must connect the same linkers at the start and end points. In this way, the primer, Linker B, can participate in PCR amplification. After PCR amplification, the fragments and single strands after enrichment can be amplified for cloning and selection. This method can also detect the efficiency of connection through PCR amplification. In molecular biology, the ligation of DNA end points is a basic operation. There are two styles of ligation: cohesive and blunt end ligation. The efficiency of cohesive end ligation is very high, but this does not occur frequently. However, the efficiency of blunt end ligation is very low and it occurs frequently. In this study, the linker and fragments were joined by cohesive end ligation. In addition, the two points of one linker are dephosphorylated. In this way, the efficiency of the ligation was increased, while self-connection was avoided. During PCR amplification after ligation, we added an extension step at $72^{\circ} \mathrm{C}$ before denaturation at $94^{\circ} \mathrm{C}$. The purpose was to utilize the $3^{\prime}-5^{\prime}$ activity of the Taq polymerase to close the gap. The results indicate improved amplification efficiency. 


\section{Microsatellite enrichment}

In this study, we used magnetic beads to construct a microsatellite library. We utilized the high affinity between biotin and streptavidin to enrich for fragments cut by restriction enzymes that contained microsatellites, and then constructed the enriched microsatellite library. The number of masc-clones is several times higher than in the conventional library. However, the microsatellites isolated from the enriched library cannot predict their distribution in the genome. Many factors can influence the efficiency of the enriched library. The PCR amplification before and after enrichment by magnetic beads could lead to the specific amplification of some fragments, especially the second PCR amplification after the enrichment. This could lead to reduced coverage of microsatellites in the genome. In this study, some microsatellites had the same core and flanking sequences. It has been suggested that PCR amplification during the enrichment step leads to uniform linkage of DNA fragments to the T-vector. For this reason, during the enrichment process, the cycles of PCR amplification should be controlled as much as possible. During enrichment, many factors influence the efficiency of amplification. For example, non-specific adsorbance between DNA and the magnetic beads due to covalent bonding between the streptavidin and the SSR probe suggests that other fragments adsorb to the magnetic beads. It is also difficult to remove nonSSR by washing with the low concentration buffer and then the high concentration buffer. In this study, the hybridization temperature of $68^{\circ} \mathrm{C}$ and washing temperature in solution II at $68^{\circ} \mathrm{C}$ could efficiently solve this problem. In this way, non-specific adsorbance was decreased to the lowest level. However, denatured single strands could easily anneal to form double strands. Therefore, binding between the labeled probe and the microsatellite, and the complementation of the template DNA will be prevented. Meanwhile, the efficiency of the enrichment will be reduced. To solve this problem, we added significant amounts of Linker B to the hybridization solution. These linkers can competitively bind the fragmented DNA to prevent annealing. This should be performed quickly during the enrichment process. Simultaneously, the negative reaction that was evoked through the change of temperature should be avoided.

\section{PCR amplification of fragments cut by the restriction enzyme connected to linkers}

Fragments cut by the restriction enzyme were linked to the T-vector, affinity-purified, and washed with solutions I, II, and III. The length of fragments after PCR amplification ranged from 400 to $1000 \mathrm{bp}$. According to the electrophoretogram of the recovered fragments cut by the restriction enzyme, there was a domain aggregate ranging from 400 to $500 \mathrm{bp}$. Therefore, it is possible that many restriction enzyme sites exist in the sika deer genome.

\section{Identification of positive clones}

After reclamation and purification, PCR fragments were ligated to the vector pMD18-T and transformed into $\mathrm{DH} 5 \alpha$-competent cells. The number of recombinations in this library was 1380. To quantify the positive clones, we utilized bacilli as the template and Linker B as the primer for PCR amplification. Of all the clones, 1144 were positive and 236 were idlers. Therefore, the proportion of positive clones was $82.9 \%$, and that of the idlers was $17.1 \%$. In all, 450 positive clones was sequenced by Shanghai Sangon Biological Engineering Technology \& Service Co. Ltd. To summarize the number of microsatellites after sequencing, 395 contained microsatellites. Thus, 
the proportion of microsatellites in all sequences was $87.8 \%$. The number of sequences that did not contain microsatellites was 55 . In other words, the proportion of non-microsatellites was $12.2 \%$.

\section{Evaluation of the enriched library}

We successfully constructed a library enriched for $(C A)_{n}$ microsatellites using the procedure described in the Materials and Methods. There were 395 microsatellites in this library, and the inserted size ranged from $260 \mathrm{bp}$ to $1104 \mathrm{bp}$. The average size of the inserted fragments was $584 \mathrm{bp}$. Microsatellites were classified based on the various repeat sequences. Of all the sequences, 176 microsatellites had nucleotide sequences that were flanked by $(C A)_{n}$ repeats, while 116 had nucleotide sequences flanked by $(\mathrm{GT})_{\mathrm{n}}$ repeats. In addition, there were other types of microsatellites; for instance, in 38 microsatellites the nucleotide sequences were flanked by other double base repeats, such as $(C T)_{n}$ or $(A T)_{n}$ repeats. Among the clones, 11 contained mononucleotide repeats, 31 contained tribasic repeats, 14 contained tetranucleotide repeats, and only one contained pentanucleotide repeats.

\section{Characterization of microsatellites}

Primers were designed and synthesized using sequence information from the 297 clones in the enriched library. There were six repeats in the microsatellite sequence designed primers, which is lower than the corresponding number of repeats found in mammalian species (Paniego et al., 2002). The PCR conditions for each primer pair were optimized using sika deer genomic DNA and a Mastercycler Gradient PCR System (Bio-Rad, USA), and polymorphisms were detected using the genomic DNA from 65 unrelated individuals. Of the 297 primer pairs, 245 (82.5\%) generated special products by modifying the annealing temperature (see Table 1), or the annealing and extension time. According to the structure, there were imperfect microsatellites, perfect microsatellites, and compound microsatellites (Beckman and Weber, 1992). A total of 245 new primer pairs were selected after gradient and ordinary PCR was performed. The fragments amplified by these new primers involved three types of microsatellites. There were 170 perfect microsatellites $(69.4 \%)$, 45 imperfect microsatellites (18.4\%), and 30 compound microsatellites $(12.2 \%)$. When randomly selecting 50 primer pairs, 47 (94\%) exhibited lengthy polymorphisms in the 65 individuals. The number of alleles ranged from 2 to 8 , with an average of 4.23 per microsatellite. These polymorphic microsatellite markers will be very useful for the construction of sika deer linkage mapping and parentage testing. These sika deer markers can also be applied to analyze corresponding loci in other Cervidae, including the red deer and white-lipped deer (Kimwele et al., 1998). All of these 264 novel sika deer microsatellite sequences were submitted to GenBank (accession No. HQ849628HQ849726, HQ849803-HQ849819, HQ849727-849801, HQ849578-HQ849627, HQ849740, HQ849802, and HQ849782) and were aligned with the sequences registered in GenBank, resulting in no significant homologies being identified. Characterization of the 47 new polymorphic microsatellites markers, including the GenBank accession No., microsatellite repeat sequence, sequence of the PCR primer, number of alleles, annealing temperature, observed heterozygosity, length of the alleles and the length of PCR products, are shown in Table 1.

Unfortunately, three markers were monomorphic, perhaps because of the small number of animals tested. It is possible that polymorphisms will be found if more individuals are analyzed. We have listed the characterizations of these monomorphic microsatellites, including the GenBank 
accession No., sequence of the PCR primer, annealing temperature, and the length of PCR products in Table 2 .

Table 1. Characterization of new polymorphic microsatellite markers identified in sika deer.

\begin{tabular}{|c|c|c|c|c|c|c|c|}
\hline Marker name & GenBank accession No. & Primer sequence & Allele size (bp) & Repeat motif & $N_{\mathrm{A}}$ & $\operatorname{Tm}\left({ }^{\circ} \mathrm{C}\right)$ & $H_{0}$ \\
\hline \multirow[t]{2}{*}{ DM1 } & HQ849578 & 5'-ATGCGAACAGGTGACTTT-3' & $102-107$ & (CA) & 2 & 58 & 0.5537 \\
\hline & & 5'-CACCGTTTCTTACAATCTCA-3' & & & & & \\
\hline \multirow[t]{2}{*}{ DM2 } & HQ849579 & 5'-GGGTCAGGTTCTCAGTTTCT-3' & $252-281$ & (CA) & 2 & 59 & 0.7385 \\
\hline & & 5'-CACCGTTTCTTACAATCTCA-3' & & & & & \\
\hline \multirow[t]{2}{*}{ DM3 } & HQ849580 & 5'-ACGATCCATCAGCCTACC-3' & $111-331$ & (CA) & 2 & 56 & 0.6203 \\
\hline & & 5'-GCACTTCTCTGTATTATCTCA-3' & & & & & \\
\hline \multirow[t]{2}{*}{ DM4 } & HQ849581 & 5'-CGACGACCAGTCAGTGTACC-3' & $329-370$ & (GT) & 2 & 61 & 0.6912 \\
\hline & & 5'-GAAAGGTCTGTCTTGGGATG-3' & & & & & \\
\hline \multirow[t]{2}{*}{ DM5 } & HQ849582 & 5'-ATTCCCTTCTGGTGGTTG-3' & $122-132$ & (GT) & 2 & 50 & 0.5231 \\
\hline & & 5'-CAGGCTTACACTTATGCTC-3' & & & & & \\
\hline \multirow[t]{2}{*}{ DM6 } & HQ849583 & 5'-GCTGCTGGCTGATGGTTG-3' & $101-212$ & (GT) & 4 & 52 & 0.8235 \\
\hline & & 5'-GGAAATGCGAACAGGTGA-3' & & & & & \\
\hline \multirow[t]{2}{*}{ DM7 } & HQ849584 & 5'-ACGATCATAGTGAAAGGCAAGA-3' & $104-118$ & (CA) & 3 & 56 & 0.5231 \\
\hline & & 5'-CTGTGCTGTTGTGAATGGGTA-3' & & & & & \\
\hline \multirow[t]{2}{*}{ DM8 } & HQ849585 & 5'-AAAGCCTGGTCTGAAGTT-3' & $102-115$ & (CA) & 2 & 56 & 0.6769 \\
\hline & & 5'-GCAGTAGAAACTCAGTCTTAAC-3' & & & & & \\
\hline \multirow[t]{2}{*}{ DM9 } & HQ849586 & 5'-TCATTCTTTCCTGGGACTTT-3' & $109-125$ & (CA) & 7 & 59 & 0.5846 \\
\hline & & 5'-TTGTATCTTAGGCGACTGG-3' & & & & & \\
\hline \multirow[t]{2}{*}{ DM10 } & HQ849587 & 5'-TGCTGTTGTGAATGGGTA-3' & $104-251$ & (GT) & 8 & 58 & 0.6615 \\
\hline & & 5'-GGATTAGCTGGATTGTGC-3' & & & & & \\
\hline \multirow[t]{2}{*}{ DM11 } & HQ849588 & 5'-ATGCGAACAGGTGACTTT-3' & $101-173$ & (CA) & 6 & 56 & 0.8154 \\
\hline & & 5'-GTGCTGTTGTGAATGGGT-3' & & & & & \\
\hline \multirow[t]{2}{*}{ DM12 } & HQ849589 & 5'-GGGTCAGGTTCTCAGTTT-3' & $103-125$ & (CA) & 3 & 58 & 0.6923 \\
\hline & & 5'-CACCGTTTCTTACAATCTCA-3' & & & & & \\
\hline \multirow[t]{2}{*}{ DM13 } & HQ849590 & 5'-ACTCAGGCAAGTCATACACACA-3' & $111-174$ & (CA) & 5 & 54 & 0.600 \\
\hline & & 5'-GGGTTAGCACCTCAACAT-3' & & & & & \\
\hline \multirow[t]{2}{*}{ DM14 } & HQ849591 & 5'-TTACCATTTGAGCCACCA-3' & 101-138 & (GT) & 3 & 54 & 0.6308 \\
\hline & & 5'-ACGATCTTGCCAAAGTTCTTCACAC-3' & & & & & \\
\hline \multirow[t]{2}{*}{ DM15 } & HQ849592 & 5'-ATGCGAACAGGTGACTTT-3' & $101-159$ & (CA) & 4 & 61 & 0.5538 \\
\hline & & 5'-CACCGTTTCTTACAATCTCA-3' & & & & & \\
\hline \multirow[t]{2}{*}{ DM16 } & HQ849593 & 5'-TGTGCTGTTGTGAATGGGTA-3' & $108-119$ & (GT) & 6 & 58 & 0.6000 \\
\hline & & 5'-CATAGTGAAAGGCAAAATCC-3' & & & & & \\
\hline DM17 & HQ849594 & 5'-CTGCCCTGCTCAAATCAC-3' & $105-271$ & (GT) & 6 & 56 & 0.7231 \\
\hline & & 5'-AAGACTGCTGCTTGGACC-3' & & & & & \\
\hline DM18 & HQ849595 & 5'-ACGATCCTGGGAGAATAT-3' & $124-295$ & (CA) & 6 & 56 & 0.7077 \\
\hline & & 5'-ATGGCTATGTATCGGTCA-3' & & & & & \\
\hline DM19 & HQ849596 & 5'-GGGTCAGGTTCTCAGTTT-3' & 118-292 & (CA) & 6 & 51 & 0.7077 \\
\hline & & 5'-CACCACCACCATCAGACAG-3' & & & & & \\
\hline DM20 & HQ849597 & 5'-GAAAGGCAAAATCCAGAGTC-3' & $106-168$ & (CA) & 4 & 59 & 0.6462 \\
\hline & & 5'-GGGTTACCAACAGCCAAGTT-3' & & & & & \\
\hline DM21 & HQ849598 & 5'-TGCTGCTGTGAATGGGTA-3' & $111-197$ & (GT) & 6 & 59 & 0.7385 \\
\hline & & 5'-AGGAGTCAGGTTCTCAGTTTC-3' & & & & & \\
\hline DM22 & HQ849599 & 5'-ACGATCATAGTGAAAGGCA-3' & $104-222$ & (CA) & 5 & 50 & 0.7538 \\
\hline & & 5'-CACCGTTTCTTACAATCTCA-3' & & & & & \\
\hline DM23 & HQ849600 & 5'-TGACAGTCTGTCCAGCTTTT-3' & $154-248$ & (CA) & 4 & 59 & 0.6308 \\
\hline & & 5'-TCAGTCCTGGCTGTTCATTG-3' & & & & & \\
\hline DM24 & HQ849601 & 5'-GGGTCAGGTTCTCAGTTT-3' & $182-251$ & (CA) & 5 & 50 & 0.6923 \\
\hline & & 5'-GGTCACCGTTTCTTACAAT-3' & & & & & \\
\hline DM25 & HQ849602 & 5'-GATTAGCTGGATTGTGC-3' & $104-174$ & (CA) & 6 & 50 & 0.7538 \\
\hline & & 5'-GCTGTTGTGAATGGGT-3' & & & & & \\
\hline DM26 & HQ849603 & 5'-GGGTCAGGTTCTCAGTTT-3' & $117-188$ & (CA) & 5 & 54 & 0.7231 \\
\hline & & 5'-CACCGTTTCTTACAATCTCA-3' & & & & & \\
\hline DM27 & HQ849604 & 5'-TGTGCTGTTGTGAATGGGTA-3' & $102-107$ & (GT) & 3 & 52 & 0.7077 \\
\hline & & 5'-CATAGTGAAAGGCAAAATCC-3' & & & & & \\
\hline DM28 & HQ849605 & 5'-TGTGGATTAGCTGGATTG-3' & $117-151$ & (CA) & 4 & 52 & 0.7385 \\
\hline & & 5'-GCTGTTGTGAATGGGTAA-3' & & & & & \\
\hline DM29 & HQ849606 & 5'-TGCTGTGTGAATGGGTA-3' & $101-145$ & (GT) & 4 & 50 & 0.7077 \\
\hline & & 5'-GGATTAGCTGGATTGTGC-3' & & & & & \\
\hline
\end{tabular}

Continued on next page 


\begin{tabular}{|c|c|c|c|c|c|c|c|}
\hline Marker name & GenBank accession No. & Primer sequence & Allele size (bp) & Repeat motif & $N_{\mathrm{A}}$ & $\operatorname{Tm}\left({ }^{\circ} \mathrm{C}\right)$ & $H_{0}$ \\
\hline DM30 & HQ849607 & $\begin{array}{l}\text { 5'-TGTGGATTAGCTGGATTG-3' } \\
\text { 5'-GCTGTTGTGAATGGGTAA-3' }\end{array}$ & $103-110$ & (CA) & 3 & 51 & 0.8769 \\
\hline DM31 & HQ849608 & $\begin{array}{l}\text { 5'-ACTGTAGGGTCACATGCTG-3' } \\
\text { 5'-CCTCAAAGGACCTCAGTAA-3' }\end{array}$ & $103-110$ & (GT) & 3 & 50 & 0.6000 \\
\hline DM32 & HQ849609 & $\begin{array}{l}\text { 5'-CTGCCCTGCTCAAATCAC-3' } \\
\text { 5'-ACTGCTGCTTGGACCCC-3' }\end{array}$ & $102-134$ & (GT) & 4 & 61 & 0.6154 \\
\hline DM33 & HQ849610 & $\begin{array}{l}\text { 5'-ATGCGAACAGGTGACTTT-3' } \\
\text { 5'-CACCGTTTCTTACAATCTCA-3' }\end{array}$ & $103-112$ & (CA) & 3 & 60 & 0.7231 \\
\hline DM34 & HQ849611 & $\begin{array}{l}\text { 5'-CACCGTTTCTTACAATCTC-3' } \\
\text { 5'-ACAGGTGACTTTGGGAAC-3' }\end{array}$ & $104-115$ & (GT) & 3 & 60 & 0.6154 \\
\hline DM35 & HQ849612 & $\begin{array}{l}\text { 5'-CCTGAAGTAGGAAATGGCAACC-3' } \\
\text { 5'-AATGATGACGATTTGTCCTAG-3' }\end{array}$ & $126-143$ & (CA) & 3 & 59 & 0.7231 \\
\hline DM36 & HQ849613 & $\begin{array}{l}\text { 5'-GGACGGAGCCTCAATT-3' } \\
\text { 5'-ATCTGTCTTCGGTGTTT-3' }\end{array}$ & $108-237$ & (CA) & 3 & 56 & 0.5231 \\
\hline DM37 & HQ849614 & $\begin{array}{l}\text { 5'-CATAGTGAAAGGCAAAATCC-3' } \\
\text { 5'-TCACCGTTTCTTACAATCTC-3' }\end{array}$ & $287-348$ & (CA) & 4 & 56 & 0.6000 \\
\hline DM38 & HQ849615 & $\begin{array}{l}\text { 5'-TGCTGTTGTGAATGGGTA-3' } \\
\text { 5'-CGACCATAGTGAAAGGGA-3' }\end{array}$ & $154-173$ & (GT) & 3 & 52 & 0.6154 \\
\hline DM39 & HQ849616 & $\begin{array}{l}\text { 5'-CAAACTTCCTTCCTGCCTGAC-3' } \\
\text { 5'-GTGGACAGTTATTTAAAGGAGTGG-3' }\end{array}$ & $130-213$ & (CA) & 3 & 59 & 0.4923 \\
\hline DM40 & HQ849617 & $\begin{array}{l}\text { 5'-CCTAACCTACACGGCTCT-3' } \\
\text { 5'-TGGAAACTCTGGCTGATG-3' }\end{array}$ & $106-238$ & (GT) & 6 & 61 & 0.5231 \\
\hline DM41 & HQ849618 & $\begin{array}{l}\text { 5'-TGTGCTGTTGTGAATGGGTA-3' } \\
\text { 5'-CATGTGAAAGGCAAAATCC-3' }\end{array}$ & $102-132$ & (GT) & 3 & 59 & 0.7692 \\
\hline DM42 & HQ849619 & $\begin{array}{l}\text { 5'-AAGTAGGAAATGGCAACC-3' } \\
\text { 5'-AGCCCAGAACAGCAGTAA-3' }\end{array}$ & $118-181$ & (CA) & 6 & 59 & 0.5243 \\
\hline DM43 & HQ849620 & $\begin{array}{l}\text { 5'-GTGAACAGGTAATCCAG-3' } \\
\text { 5'-CATTGCCCTGACTATTGC-3' }\end{array}$ & $108-125$ & $(\mathrm{CAA})$ & 4 & 59 & 0.7077 \\
\hline DM44 & HQ849621 & $\begin{array}{l}\text { 5'-AAGAGCAGTTTCGCAGAG-3' } \\
\text { 5'-ACCACCACCATCAGACAG-3' }\end{array}$ & $104-118$ & (CA) & 4 & 61 & 0.8154 \\
\hline DM45 & HQ849622 & $\begin{array}{l}\text { 5'-CACCGTTTCTTACAATCTCA-3' } \\
\text { 5'-AGGGGTCAGGTTCTCAGTTTCTAC-3' }\end{array}$ & $120-337$ & (GT) & 5 & 56 & 0.7231 \\
\hline DM46 & HQ849623 & $\begin{array}{l}\text { 5'-AAAGCCTGGTCTGAAGTT-3' } \\
\text { 5'-GCAGTAGAAACTCAGTCTTAAC-3' }\end{array}$ & $111-207$ & (CA) & 6 & 56 & 0.7385 \\
\hline DM47 & HQ849624 & $\begin{array}{l}\text { 5'-ACTGTGCTGTTGTGAATGGGTA-3' } \\
\text { 5'-CATAGTGAAAGGCAAAATCC-3' }\end{array}$ & $112-117$ & (GT) & 2 & 58 & 0.7692 \\
\hline
\end{tabular}

The makers code 'DM' stands for deer microsatellite markers. Column headings are as follows: $N_{A}=$ number of alleles; $\mathrm{Tm}$, annealing temperature $\left({ }^{\circ} \mathrm{C}\right) ; H_{\mathrm{O}}=$ observed heterozygosity; information content; GenBank accession No.; primer sequence; repeat motif.

Table 2. Characterization of new monomorphic sika deer microsatellite markers.

\begin{tabular}{|c|c|c|c|c|c|}
\hline Marker name & GenBank accession No. & Primer sequence & Repeat motif & Length (bp) & $\operatorname{Tm}\left({ }^{\circ} \mathrm{C}\right)$ \\
\hline \multirow[t]{2}{*}{ DM48 } & HQ849625 & 5'-GGGTCAGGTTCAGTTTCT-3' & (CA) & 456 & 50 \\
\hline & & 5'-CACCGTTTCTTACAATCTCA-3' & & & \\
\hline \multirow[t]{2}{*}{ DM49 } & HQ849626 & 5'-TGGCGACCTGATGTGA-3' & (CA) & 356 & 57 \\
\hline & & 5'-АТСтСтстСтСтстСтстTтСтСтG-3' & & & \\
\hline \multirow[t]{2}{*}{ DM50 } & HQ849627 & 5'-CACGTCTGCCCTGCCCTGAG-3' & (CA) & 388 & 56 \\
\hline & & 5'-GGGGTCAGGTTCTCAGTTTCTACA-3' & & & \\
\hline
\end{tabular}

Makers code DM stands for deer microsatellite markers. Column headings are as follows: GenBank accession No.; primer sequences; repeat motif, length of fragments, Tm, annealing temperature.

The sika deer is a unique, endangered animal found in East Asia. Historically, sika deer resources were very rich and these animals were extreme widely distributed, but because of natural and human factors, the Chinese sika deer have been reduced from six to three subspecies: the Sichuan, Northeast Asia, and South Asia species. Their distribution has drastically reduced, and these species are already bordering on extinction. 
Although microsatellites are informative genetic markers, the need for prior sequence information to produce locus-specific primer sets is a major limitation. Traditionally, microsatellite loci have been isolated from partial genomic libraries (selected for small insert size) from the species of interest, and several thousands of clones are screened through colony hybridization with repeat containing probes (Rassmann et al., 1991). Although relatively simple, especially for microsatellite-rich genomes, this approach can be extremely tedious and inefficient for species with low microsatellite frequencies, such as the Cervidae species. Several procedures for microsatellite library enrichment have been developed to improve the efficiency of microsatellite isolation. They can be classified according to the capture technique: 1) streptavidin-coated magnetic beads; 2) microsatellite probes attached to small nylon membranes; and 3) other infrequently used procedures, such as the use of the dut ung strain of $E$. coli or the magnetic capture of phage DNA (Reed et al., 2003).

In summary, we constructed a library enriched with $(C A)_{n}$ microsatellites from which we successfully isolated new microsatellite markers. The enrichment procedure in our study is rapid and efficient at isolating microsatellites from sika deer or other animals, especially those that are currently less well studied. The polymorphic microsatellite markers that have been identified and characterized will contribute to genetic linkage mapping of deer; the construction of a comparative genetic map with other Cervidae, such as red deer and white-lipped deer, population genetics studies, and phylogenetic studies.

\section{Conflicts of interest}

The authors declare no conflict of interest.

\section{ACKNOWLEDGMENTS}

We sincerely thank Jilin Changshuang Deer Industry Co., Ltd. Special Local Product Development Group Co., Ltd. for providing sika deer blood and tissue samples. Research supported by the Science and Technology Support Program of Changchun in China (\#08KJ36).

\section{REFERENCES}

Beckman JS and Webber JL (1992). Survey of human and rat microsatellites. Genomics 12: 627-631.

Buchholz WG, Pearce JM, Pierson BJ and Scribner KT (1998). Dinucleotide repeat polymorphisms in waterfowl (family Anatidae): characterization of a sex-linked (Z-specific) and 14 autosomal loci. Anim. Genet. 29: 323-325.

Chakraborty R, Kimmer M, Stivers DN, Davison LJ, et al. (1997). Relative mutation rates at di-, tri-, and tetranucleotide microsatellite loci. Proc. Natl. Acad. Sci. U. S. A. 94: 1041-1046.

Chowdhury S and Bansal M (2001). Modelling studies on neurodegenerative diseasecausing triplet repeat sequences d(GGC/ GCC $)_{n}$ and d(CAG/CTG $)_{n}$. J. Biosci. 26: 649-665.

Crittenden LB, Provencher L, Santangelo L, Levin I, et al. (1993). Characterization of a red jungle fowl by white leghom backcross reference population for molecular mapping of the chicken genome. Poult. Sci. 72: 334-348.

Ellegren $\mathrm{H}$ (2000). Heterogeneous mutation processes in human microsatellite DNA sequences. Nat. Genet. $24: 400-402$.

Fischer D and Bachmann K (1998). Microsatellite enrichment in organisms with large genomes. BioTechniques 24: 796-802.

Huang Y, Tu J, Cheng X, Tang B, et al. (2005). Characterization of 35 novel microsatellite DNA markers from the duck (Anas platyrhynchos) genome and cross-amplification in other birds. Genet. Sel. Evol. 37: 55-72.

Jakše $\mathrm{J}$ and Branka J (2001). High throughput isolation of microsatellites in Hop (Humulus lupulus L). Plant Mol. Biol. Rep. 19: $217-226$.

Kandpal RP, Kandpal G and Weissman SM (1994). Construction of libraries enriched for sequence repeats and jumping clones, and hybridization selection for region specific markers. Proc. Natl. Acad. Sci. U. S. A. 91: 88-92. 
Kimwele CN, Graves JA, Burke T and Hanotte O (1998). Development of microsatellite markers for parentage typing of chicks in the ostrich Struthio camelus. Mol. Ecol. 7: 247-255.

Lü X, Wei F, Li M, Yang G, et al. (2006). Genetic diversity among Chinese sika deer (Cervus nippon) populations and relationship between Chinese and Japanese sika deer. Chin. Sci. Bull. 4: 433-440.

Paniego N, Echaide M, Muñoz M, Fernández L, et al. (2002). Microsatellite isolation and characterization in sunflower (Helianthus annuus L.). Genome 45: 34-43.

Rassmann K, Schlotterer C and Tauz D (1991). Isolation of simple sequence loci for use in polymerase chain reaction-based DNA fingerprinting. Electrophoresis 12: 113-118.

Reed KM, Chaves LD, Garbes JR, Da Y, et al. (2003). Allelic variation and genetic linkage of avian microsatellites in a new turkey population for genetic mapping. Cytogenet. Genome Res. 102: 331-339.

Sahoo S and Kashyap V (2005). Influence of language and ancestry on genetic structure of contiguous populations: A microsatellite based study on populations of Orissa. BMC Genet. 6: 4-4.

Stallings RL, Ford AF, Nelson D, Torney DC, et al. (1991). Evolution and distribution of (GT)n repetitive sequences in mammalian genomes. Genomics 10: 807-815.

Tamate HB and Tsuchiya T (1995). Mitochondrial DNA polymorphism in subspecies of the Japanese sika deer (Cervus nippon). J. Hered. 86: 211-215.

Tamate HB, Shibata K, Tsuchiya T and Ohtaishi N (1995). Assessment of genetic variations within populations of sika deer in Japan by analysis of randomly amplified polymorphic DNA (RAPD). Zool. Sci. 12: 669-673.

Tautz D and Renz M (1984). Simple sequences are ubiquitous repetitive components of eukaryotic genomes. Nucleic Acids Res. 12: 4127-4138.

Zhang X (2007). A standards system for the protection and utilization of wild fauna and flora in China. China Standardization 7: $11-18$. 